\title{
THE INFLUENCE OF PRESSURE AND TEMPERATURE ON THE COMPRESSIBILITY FACTOR
}

\author{
Oprea George Iulian ${ }^{1}$, Aidoni Artemis ${ }^{2}$, Mitrea Ioana Cornelia ${ }^{3}$, Dinu Florinel ${ }^{4}$
}

${ }^{1}$ S.C. Petrostar S.A. Ploiesti, Romania

${ }^{2}$ ENEL Romania S.A., Romania

${ }^{3}$ OMV Petrom S.A., Romania

${ }^{4}$ Petroleum-Gas University of Ploiesti, Romania

e-mail: oprea.iulian10@yahoo.com, artemis.aidoni@enel.com

\section{DOI: 10.51865/JPGT.2021.02.02}

\begin{abstract}
The natural gas compressibility factor indicates the compression and expansion characteristics of natural gas under different conditions. It is a thermodynamic property used to take into account the deviation of the behaviour of real natural gases from that of an ideal gas. Compressibility factor, Z, values of natural gases are necessary for most petroleum gas engineering calculations.

In this study, a comparison between five different calculation methods is presented to determine this critical parameter for the same natural gas at different conditions (pressure and temperature), using Canadian Association of Petroleum Producers, Azizi, Behbahani and Isazadeh, Dranchuk- Purvis- Robinson, Dranchuk-Abu-Kassem and Standing- Katz methods.

The correlations are based on the equation of state are often implicit because they require iteration. Many correlations have been derived to enhance simplicity; however, no correlation has been developed for the entire range of pseudo-reduced pressures and temperatures. Azizi, Behbahani and Isazadeh's method was found to have the biggest error as a result obtained for $\mathrm{T}=20^{\circ} \mathrm{C}$, and $\mathrm{p}=20$ bar is no longer in the field of applicability.
\end{abstract}

Keywords: gas compressibility factor; correlation; equations of state (EOSs); pressure; temperature;

\section{INTRODUCTION}

"Critical insight into the behaviour of natural gas is important to the reservoir and the chemical engineering calculations that deal with gas as one of the main phases. Among the parameters of evaluating the performance of natural gas, the compressibility is of highest importance in the determination of the natural gas phase behaviour." [3]

The compressibility factor $(\mathrm{Z})$ is a dimensionless coefficient used to modify the thermal equation of state of the ideal gas to correspond to the behaviour of a real gas. In this sense, the compressibility factor can be interpreted as a physical property of gases, its value depending on the pressure, temperature and nature of the gas. The gas compressibility factor is required for gas reservoir engineering calculations which 
include the estimation of gas reserves, design of oil and gas separators and design of pipelines for the transmission of produced gas, among others.

In general, the deviation of a gas from the behaviour of the ideal gas becomes significant in the vicinity of the saturation curve (at phase change), or at low temperatures, or at high pressures. The most precise way to determine gas compressibility factor is laboratory analysis, but in the absence of laboratory data correlations are feasible alternatives for estimating the compressibility factor.

The values of the compressibility factor are calculated from the equations of state usually written in viral form, in which the constants are determined empirically. Its values for a given gas can also be extracted from a universal diagram that represents $\mathrm{Z}$ as a function of low pressure, having as a parameter the low temperature.

The $\mathrm{Z}$ factor, equation (1), is the volume occupied by the amount of gas and the same amount of ideal gas:

$\mathrm{Z}=\frac{\text { Vactual }}{\text { Videal }}$

Substituting in the relation of the ideal gas, equation (2) Videal results:

$\mathrm{PV}_{\text {actual }}=\mathrm{ZnRT}$

Where $\mathrm{P}$ is the pressure, $\mathrm{V}$ is the volume, $\mathrm{T}$ is the absolute temperature, $\mathrm{Z}$ is the compressibility factor, $\mathrm{n}$ is the number of kilo-moles of the gas, and $\mathrm{R}$ is the gas constant. The gas deviation factor, $\mathrm{z}$, is close to 1 at low pressure and high temperature, which means that the gas behaves like an ideal gas in these conditions. At standard or atmospheric conditions, the gas $\mathrm{z}$ factor is always approximately 1 .

\section{HISTORY OF THE Z-FACTOR CORRELATIONS}

"Probably the most widely accepted correlation for natural gas mixtures is the StandingKatz (S-K) Z-factor chart" [1]. The S-K chart was developed using data for binary mixtures of methane with propane, ethane, butane, and natural gases having a wide range of composition. Actually, the $\mathrm{S}-\mathrm{K}$ chart is a continuation and modification of a generalized Z-factor chart developed by Brown and Holcomb $(\mathrm{BH})$. Those two charts are identical at reduced pressures less than 4 . Above this value, the $\mathrm{BH}$ chart was found to be consistently inaccurate. "Therefore, Standing and Katz used data from 16 natural gas mixtures, along with methane Z-factors as a guide, to extend the chart to reduced pressures of 15." [2] Since the publication in 1941 of the S-K chart, several correlations have been developed which successfully extended the chart.

Studies of the gas compressibility factors for natural gases of various compositions have shown that compressibility factors can be generalized with sufficient accuracies for most engineering purposes when they are expressed in terms of the following two dimensionless properties:

- Pseudo- reduced pressure

- Pseudo-reduced temperature

As illustrated in Figure 1 The Standing-Katz Correlation correlates the z-factor to the Pseudo-Reduced Pressure, ppr, and Pseudo-Reduced Temperature, Tpr. The pseudoreduced properties are defined by equations (3) and (4): 


$$
\begin{aligned}
& P_{p r}=\frac{P}{P_{p c}} \\
& T_{p r}=\frac{T}{T_{p c}}
\end{aligned}
$$

where, $\mathrm{P}=$ system pressure, $\mathrm{psia}$

$$
\mathrm{P}_{\mathrm{pr}}=\text { pseudo- reduced pressure, dimensionless }
$$

$\mathrm{T}=$ system temperature, ${ }^{\circ} \mathrm{C}$

$\mathrm{T}_{\mathrm{pr}}=$ pseudo- reduced temperature, dimensionless

$\mathrm{P}_{\mathrm{pc}}, \mathrm{T}_{\mathrm{pc}}=$ pseudo- critical pressure and temperature, respectively, and defined by the following relationships, equations (5)-(6):

$P_{p c}=\sum_{i=1} y_{i} P c i$

$T_{p c}=\sum_{i=1} y_{i} T c i$

In these equations, Tci and Pci provide the values for the critical temperature and pressure of component $i$. Also, $y_{i}$ describe the mole fraction of component $i$.

It should be pointed out that these pseudo- critical properties, i.e., $\mathrm{P}_{\mathrm{pc}}$ and $\mathrm{T}_{\mathrm{pc}}$, do not represent the actual critical properties of the gas mixture. These pseudo proprieties are used as correlating parameters in generating gas properties.

"Natural gases that contain $\mathrm{H}_{2} \mathrm{~S}$ and or $\mathrm{CO}_{2}$ frequently exhibit different compressibilityfactors behaviour than do sweet gases. Wichert and Aziz (1972) developed a simple, easy-to-use calculation procedure to account for these differences. This method permits the use of the Standing- Katz chart by using a pseudo-critical temperature adjustment factor, which is a function of the concentration of $\mathrm{CO}_{2}$ and $\mathrm{H}_{2} \mathrm{~S}$ in the sour gas.' [4] The correction factor resulted is then used for the adjustment of the pseudo-critical parameters (temperature and pressure) according to the following expressions, equation (7) and (8):

$T_{p c}^{\prime}=T_{p c}-\varepsilon$

$P_{p c}^{\prime}=\frac{P_{p c} T^{\prime} p c}{T_{p c}+B(1-B) \varepsilon}$

where $\mathrm{T}_{\mathrm{pc}}=$ pseudo- critical temperature, ${ }^{\circ} \mathrm{R}$

$\mathrm{P}_{\mathrm{pc}}=$ pseudo- critical pressure, psia

$\mathrm{T}_{\mathrm{pc}}=$ corrected pseudo- critical temperature, ${ }^{\circ} \mathrm{R}$

$\mathrm{P}_{\mathrm{pc}}{ }_{\mathrm{pc}}=$ corrected pseudo- critical pressure, psia

$\mathrm{B}=$ mole fraction of $\mathrm{H}_{2} \mathrm{~S}$ in the gas mixture

$\varepsilon=$ pseudo-critical temperature adjustment factor and is defined mathematically by the following expression, equation (9):

$\varepsilon=120\left[A^{0.9}-A^{1.6}\right]+\left(B^{0.5}-B^{4.0}\right)$

where the coefficient $\mathrm{A}$, equation (10), is the sum of the mole fraction $\mathrm{H}_{2} \mathrm{~S}$ and $\mathrm{CO}_{2}$ in the gas mixture, or:

$A=y_{\mathrm{H}_{2} \mathrm{~S}}+y_{\mathrm{CO}_{2}}$ 


\section{GAS COMPRESSIBILITY FACTOR CORRELATIONS}

In this present study, the compressibility factor was calculated by using five methods:

\section{a. Canadian Association of Petroleum Producers Method}

The calculation equation (11) used for this method is:

$\mathrm{ZCAaI}=\frac{1}{\left[1+\frac{527383 \cdot\left(P_{a I}-P_{0}\right) 10^{1.785 \cdot 8 r g}}{\left(t_{a I}+T_{0}\right)^{3.825}}\right]}=0.968$

\section{b. Azizi, Behbahani and Isazadeh Method}

For this method were used the coefficients according to the Table 1 and euqations (12)-(17).

Table 1: The Coefficients of Azizi, Behbahani and Isazadeh Method

\begin{tabular}{|c|c|c|c|}
\hline $\mathrm{a}$ & 0.037314248539 & $\mathrm{~b}$ & 0.014080715149 \\
\hline $\mathrm{c}$ & 0.016326324539 & $\mathrm{~d}$ & 0.030777647882 \\
\hline $\mathrm{e}$ & 13843575480.94 & $\mathrm{f}$ & 16799138540.76 \\
\hline $\mathrm{g}$ & 1624178942.65 & $\mathrm{~h}$ & 13702270281.09 \\
\hline $\mathrm{i}$ & 41645509.90 & $\mathrm{j}$ & 237249967625.01 \\
\hline $\mathrm{k}$ & 24449114791.15 & $\mathrm{l}$ & 19357955749.33 \\
\hline $\mathrm{m}$ & -126354717916.61 & $\mathrm{n}$ & 623705678.39 \\
\hline $\mathrm{o}$ & 17997651104.33 & $\mathrm{p}$ & 151211393445.06 \\
\hline $\mathrm{q}$ & 139474437997.17 & $\mathrm{r}$ & -24233012984.10 \\
\hline $\mathrm{s}$ & 18938047327.52 & $\mathrm{t}$ & -141401620722.69 \\
\hline
\end{tabular}

$A=a \cdot T_{\text {praI }}^{2.16}+b \cdot P_{\text {praI }}^{1.028}+c \cdot P_{\text {praI }}^{1.58} \cdot T_{\text {praI }}^{-2.1}+d \cdot \operatorname{In}\left(T_{\text {praI }}^{-0.5}\right)$

$\mathrm{B}=e+f \cdot T_{\text {praI }}^{2.4}+g \cdot P_{\text {praI }}^{1.56}+h \cdot P_{\text {praI }}^{0.124} \cdot T_{\text {praI }}^{3.033}$

$\mathrm{C}=\quad i \cdot \operatorname{In}\left(T_{\text {praI }}^{-1.28}\right)+j \cdot \operatorname{In}\left(T_{\text {praI }}^{1.37}\right)+k \cdot \operatorname{In}\left(p_{\text {praI }}\right)+i \cdot \operatorname{In}\left(P_{\text {praI }}^{2}\right)+m \cdot \operatorname{In}\left(P_{\text {PraI }}\right) \cdot$

In $\left(T_{\text {praI }}\right)$

$\mathrm{D}=1+n \cdot T_{\text {praI }}^{5.55}+o \cdot P_{\text {praI }}^{0.68} \cdot T_{\text {praI }}^{0.33}$

$\mathrm{E}=\quad p \cdot \operatorname{In}\left(T_{\text {praI }}^{1.18}\right)+q \cdot \operatorname{In}\left(T_{\text {praI }}^{2.1}\right)+r \cdot \operatorname{In}\left(P_{\text {PraI }}\right)+s \cdot \operatorname{In}\left(P_{\text {praI }}^{2}\right)+t \cdot \operatorname{In}\left(P_{\text {praI }}\right) \cdot$

$\operatorname{In}\left(T_{\text {praI }}\right)$

$z_{a z}=A+\frac{B+C}{D+E}$

\section{c. Dranchuk-Purvis-Robinson Method}

Dranchuk, Purvis and Robinson (1974) developed a correlation-based the BenedictWebb-Rubin type of equation of state. The eight coefficients of the proposed equations were optimized by fitting the equation to 1,500 data points from the Standing and Katz Z-Factor chart. The general equation (18) of the method has the following form:

$Z=1+\left(A_{1}+\frac{A_{2}}{\text { TpraI }}+\frac{A_{3}}{\text { TpraI }^{3}}\right) R_{a}+\left(A_{4}+\frac{A_{5}}{\text { TpraI }}\right) R_{a}{ }^{2}+\left(A_{5} \cdot \frac{A_{6}}{\text { Tpral }}\right) R_{a}{ }^{5}+$

$A_{7} \frac{R_{a}{ }^{2}}{\text { TpraI }^{3}}\left(1+A_{8} \cdot R_{a}{ }^{2}\right) e^{\left(-A_{8} \cdot R_{a}{ }^{2}\right)}$ 
where $\mathrm{R}_{\mathrm{a}}=$ reduced gas density, equation (21) and (23)

The coefficients A1 through A8 have the following values:

Table 2 The Coefficients of Dranchuk - Purvis - Robinson Method

\begin{tabular}{|c|c|c|c|}
\hline A & A value & A & A value \\
\hline A1 & 0.31506237 & A5 & -0.61232032 \\
\hline A2 & -1.0467099 & A6 & -0.10488813 \\
\hline A3 & -0.57832729 & A7 & 0.68157001 \\
\hline A4 & 0.53530771 & A8 & 0.68446549 \\
\hline
\end{tabular}

The method is valid within the following ranges of pseudo-reduced temperature (19) and pressure (20):

$$
\begin{aligned}
& 1,05 \leq \text { Tpral } \leq 3,0 \\
& 0,2 \leq \text { Ppral } \leq 3,0 \\
& R_{a 1 I}=\frac{0.27 \cdot \text { PpraI }}{1 \cdot \text { TpraI }} \\
& \mathrm{R}_{\mathrm{a} 1 \mathrm{I}}=0,059 \\
& \mathrm{Z}_{1 \mathrm{drp} 1}=\left[1+\left[0.31506237-\frac{1.0467099}{\text { TpraI }}-\left(\frac{0.57832729}{\text { TpraI }^{3}}\right)\right] \cdot R_{a 1 I}+[0.53530771-\right. \\
& \left.\left.\left(\frac{0.6123032}{\text { TpraI }}\right)\right] \cdot R_{a 1 I}^{2}+\frac{(-0.6123032) \cdot 0.10488813}{\text { TpraI }^{2}} \cdot R_{a 1 I}^{5}\right]+\left[\left(\frac{0.68157001 \cdot R_{a 1 I^{2}}}{\text { TpraI }^{3}}\right) \cdot\right. \\
& \left.\left(1+0.68116519 \cdot R_{a 1 I}^{2}\right) \cdot e^{-\left(0.68116519 \cdot R_{a 11}{ }^{2}\right.}\right] \\
& R_{a 2 I}=\frac{0.27 \cdot \text { PpraI }}{Z_{1 \text { drpI }} \cdot \text { TpraI }} \\
& \mathrm{R}_{\mathrm{a} 2 \mathrm{I}}=0.061 \\
& Z_{2 d p r I}= \\
& {\left[\begin{array}{c}
1+\left[0.31506237-\frac{1.0467099}{T_{p r a I}}-\left(\frac{0.57832729}{T_{p r a I}^{3}}\right)\right] \cdot R_{\mathrm{a} 2 I}+ \\
{\left[0.53530771-\left(\frac{0.6123032}{\text { TpraI }}\right)\right] \cdot R_{\mathrm{a} 2 I}^{2}+\frac{(-0.6123032) \cdot 0.10488813}{T_{p r a I}} \cdot R_{\mathrm{a} 2 I}^{5}}
\end{array}\right]+\left[\left(\frac{0.68157001 \cdot R_{\mathrm{a} 2 I}^{2}}{T_{\text {praI }}^{3}}\right) .\right.} \\
& \left.\left(1+0.68116519 \cdot R_{\mathrm{a} 2 I}^{2}\right) \cdot e^{-\left(0.68116519 \cdot R_{\mathrm{a} 2 I}^{2}\right)}\right] \\
& Z_{d p r}=\frac{Z_{1 d p r I}+Z_{2 d p r I}}{2}
\end{aligned}
$$

From the general expression of formula (18) resulted equations (22) and (24) and the final value taken into account is that of equation (25).

d. Equation of State, Dranchuk - Abu Kassem for Gas Z Factor calculating.

Dranchuk and Abu-Kassem (1975) derived an analytical expression for calculating the reduced gas density that can be used to estimate the gas compressibility factor.

This is based on the following equations (26)-(31):

$z=1+c_{1} * \rho_{r}+c_{2} * \rho_{r}^{2}-c_{3} * \rho_{r}^{5}+c_{4}$

Where:

$\rho_{r}=\frac{0.27 * \rho_{r}}{z * T_{p r}}$ 


$$
\begin{aligned}
& c_{1}=A_{1}+\frac{A_{2}}{T_{p r}}+\frac{A_{3}}{T_{p r}^{3}}+\frac{A_{4}}{T_{p r}^{4}}+\frac{A_{5}}{T_{p r}^{5}} \\
& c_{2}=A_{6}+\frac{A_{7}}{T_{p r}}+\frac{A_{8}}{T_{p r}^{2}} \\
& c_{3}=A_{9} *\left(\frac{A_{7}}{T_{p r}}+\frac{A_{8}}{T_{p r}^{2}}\right) \\
& c_{4}=A_{10} *\left(1+A_{11} * \rho_{r}^{2}\right) *\left(\frac{\rho_{r}^{2}}{T_{p r}^{3}}\right)-\exp \left(-A_{11} * \rho_{r}^{2}\right)
\end{aligned}
$$

Table 3 The Coefficients of Dranchuk and Abou-Kassem Method

\begin{tabular}{|c|c|c|c|}
\hline A & A value & A & A value \\
\hline A1 & 0.32650 & A7 & -0.73610 \\
\hline A2 & -1.07000 & A8 & 0.18440 \\
\hline A3 & -0.53390 & A9 & 0.10560 \\
\hline A4 & 0.01569 & A10 & 0.61340 \\
\hline A5 & -0.05165 & A11 & 0.72100 \\
\hline A6 & 0.54750 & & \\
\hline
\end{tabular}

e. Standing and Katz Graphical Correlation

This relation is a function of the pseudoreduced pressure, $\mathrm{p}_{\mathrm{r}}$, and pseudoreduced temperature, $\mathrm{T}_{\mathrm{r}}$.

After calculating $p_{r}$ and $T_{r}$, these values are entered in the respective axis, and at the intersection point, it is obtained the $\mathrm{Z}$ factor.

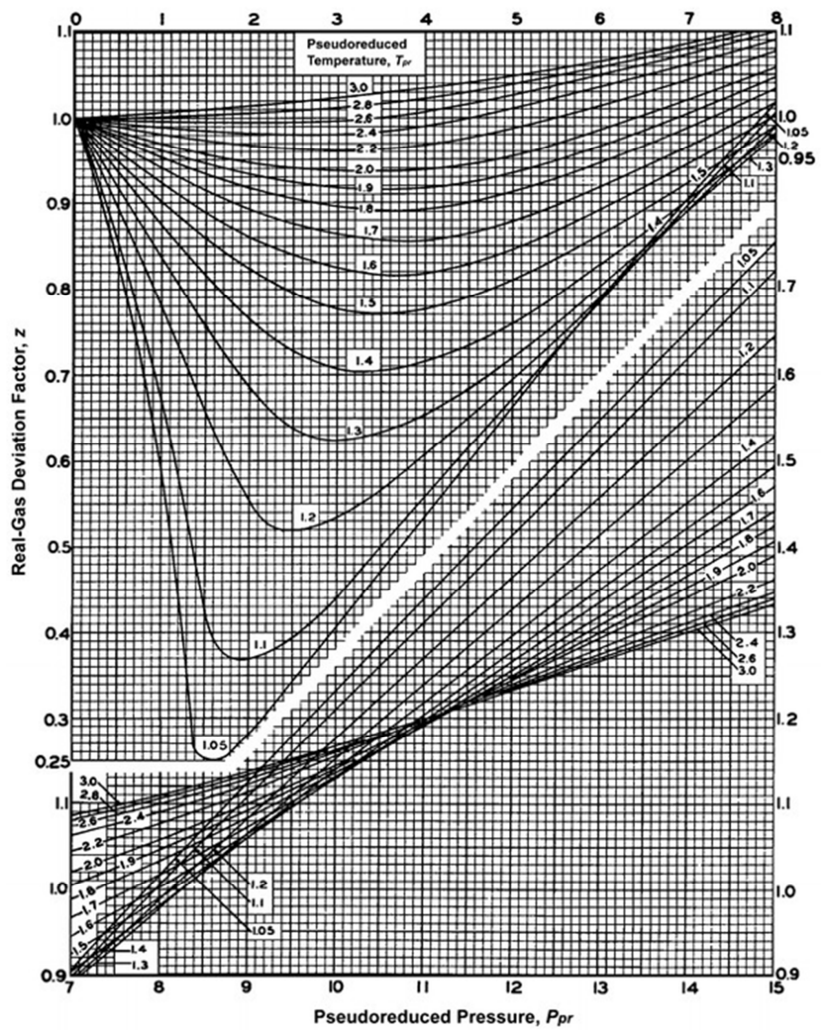

Fig. 1 Standing-Katz Correlation for Z-Factors of Hydrocarbon Gases [1] 
Table 4 The composition of the gas analyzed

\begin{tabular}{|c|c|}
\hline Component & Mole Fraction \% \\
\hline Methane & 97.3359 \\
\hline Etan & 1.2283 \\
\hline Propane & 0.3713 \\
\hline Iso-butane & 0.0905 \\
\hline N-butane & 0.0902 \\
\hline Iso-pentane & 0.0363 \\
\hline N-pentane & 0.0241 \\
\hline N-hexane & 0.0426 \\
\hline N-heptane & 0.0292 \\
\hline N-octane & 0.0133 \\
\hline Helium & 0.0068 \\
\hline Azote & 0.5719 \\
\hline Oxygen & 0.0056 \\
\hline Carbon dioxide & 0.1538 \\
\hline
\end{tabular}

Table 5 The results obtained for the $Z$ factor

\begin{tabular}{|c|c|c|c|c|}
\hline Method & $\begin{aligned} \mathrm{P} & =15 \text { bar, } \\
\mathrm{T} & =15^{\circ} \mathrm{C}\end{aligned}$ & $\begin{aligned} \mathrm{P} & =15 \text { bar, } \\
\mathrm{T} & =20^{\circ} \mathrm{C}\end{aligned}$ & $\begin{aligned} \mathrm{P} & =20 \text { bar, } \\
\mathrm{T} & =20^{\circ} \mathrm{C}\end{aligned}$ & $\begin{aligned} \mathrm{P} & =20 \text { bar, } \\
\mathrm{T} & =15^{\circ} \mathrm{C}\end{aligned}$ \\
\hline Azizi, Behbahani and Isazadeh & 0.936 & 0.948 & 1.006 & 0.997 \\
\hline $\begin{array}{ll}\text { Canadian Association } & \text { of } \\
\text { Petroleum Producers } & \\
\end{array}$ & 0.9684 & 0.97 & 0.961 & 0.958 \\
\hline Dranchuk-Purvis- Robinson & 0.967 & 0.968 & 0.958 & 0.956 \\
\hline Dranchuk and Abu-Kassem & 0.942 & 0.946 & 0.936 & 0.931 \\
\hline $\begin{array}{l}\text { Standing and Katz Graphical } \\
\text { Correlation }\end{array}$ & 0.97 & 0.975 & 0.96 & 0.955 \\
\hline
\end{tabular}

\section{CONCLUSION}

The $Z$-factor is an essential parameter in most petroleum engineering calculations. Accurate measurement and analysis of compressibility factor are significant. The following are the main conclusions that can be withdrawn from this study:

Determination of accurate, critical parameters of mixtures is an essential step in order to obtain precise compressibility factor value.

Following the calculations performed on the same gaseous composition at a pressure of 20 bar and a temperature of $20{ }^{\circ} \mathrm{C}$, the Azizi, Behbahani and Isazadeh method is no longer in the field of applicability as evidenced by the result obtained.

The experimental trend of the gas compressibility factor showed that by increasing the temperature, the Z-factor also increases.

As can be seen from the results obtained, in the first method used, compresiblity factor increases with pressure and in the other methods used, it is the other way around.

Regarding the Standing and Katz Graphical Correlation method, it cannot been 
considered very accurate, being a graphical method, which can significantly influence the results obtained.

It can be seen that the values obtained through the Canadian Association of Petroleum Producers, Dranchuk-Purvis-Robinson and the Standing and Katz Graphical Correlation graphical methods resulted in close values. Furtermore, comparing the results obtained with the Azizi, Behbahani and Isazadeh methods and Dranchuk and Abu-Kassem with the 3 methods mentioned above there are differences but not considerable.

The Azizi, Behbahani and Isazadeh and the Dranchuk and Abu-Kassem method have the lowest values of the $\mathrm{Z}$ factor at low temperature and pressure, and their results are close, but with the increase of the two factors the results are distant and we have big differences. The other 3 methods have similar results at the same pressure and temperature parameters.

These comparisons indicate the superiority of the Canadian Association of Petroleum Producers, Dranchuk-Purvis-Robinson and Dranchuk and Abu-Kassem methods over the other correlations used to calculate compressibility factor of natural gases.

\section{REFERENCES}

[1] Standing M B, Katz D L., Density of Natural Gases, Trans AIME, 1942, pp 140149.

[2] Navid Azizi, R. Behbahani, M. A. Isazadeh, An efficient correlation for calculating compressibility factor of natural gases, Journal of Natural Gas Chemistry 19, January 11, 2010, pp 1-2.

[3] Abdolhossein Hemmati-Sarapardeh, Sassan Hajirezaie, Mohamad Reza Soltanian, Amir Mosavi, Narjes Nabipour, Shahaboddin Shamshirband, and Kwok-Wing Chauj, Modeling natural gas compressibility factor using a hybrid group method of data handling, Engineering Applications Of Computational Fluid Mechanics vol. 14, no. 1, 2020, pp 27-37.

[4] Tarek Ahmed, Reservoir Engineering Handbook, Second Edition, Publisher: Elsevier, ISBN: 978-0-88415-770-0, 2001, pp 45. 